IZA DP No. 7559

The Effect of Extended Unemployment Benefit on the Job Finding Hazards: A Quasi-Experiment in Japan

Tomohiro Machikita

Miki Kohara

Masaru Sasaki

August 2013 


\title{
The Effect of Extended Unemployment Benefit on the Job Finding Hazards: A Quasi-Experiment in Japan
}

\author{
Tomohiro Machikita \\ Miki Kohara \\ Osaka University \\ Masaru Sasaki \\ Osaka University \\ and IZA
}

Institute of Developing Economies (IDE-JETRO)

Discussion Paper No. 7559

August 2013

IZA
P.O. Box 7240
53072 Bonn
Germany

Phone: +49-228-3894-0

Fax: +49-228-3894-180

E-mail: iza@iza.org

\begin{abstract}
Any opinions expressed here are those of the author(s) and not those of IZA. Research published in this series may include views on policy, but the institute itself takes no institutional policy positions. The IZA research network is committed to the IZA Guiding Principles of Research Integrity.

The Institute for the Study of Labor (IZA) in Bonn is a local and virtual international research center and a place of communication between science, politics and business. IZA is an independent nonprofit organization supported by Deutsche Post Foundation. The center is associated with the University of Bonn and offers a stimulating research environment through its international network, workshops and conferences, data service, project support, research visits and doctoral program. IZA engages in (i) original and internationally competitive research in all fields of labor economics, (ii) development of policy concepts, and (iii) dissemination of research results and concepts to the interested public.
\end{abstract}

IZA Discussion Papers often represent preliminary work and are circulated to encourage discussion. Citation of such a paper should account for its provisional character. A revised version may be available directly from the author. 


\section{ABSTRACT \\ The Effect of Extended Unemployment Benefit on the Job Finding Hazards: A Quasi-Experiment in Japan*}

This paper studies how changes in extended unemployment insurance (UI) benefit affect the duration of unemployment. We investigate this question by exploiting not only strict age thresholds but also the pre-displacement tenure and the reason for separation from the previous job in the Japanese UI system which determines a worker's maximum potential UI benefit duration at the age of 45 . Job-seekers who became unemployed due to exogenous reasons (such as establishment closure) at the age threshold of 45 who have longer predisplacement tenure receive maximum benefits for longer durations. This rule creates a local randomized experiment. Using a large administrative dataset to implement a difference-indifferences approach for the narrow age range of 44-46 who entered unemployment in the same month in the same year, we find that longer maximum benefit durations do not lead to a decrease in the jobless hazard; the duration of unemployment is not prolonged among jobseekers who have longer maximum benefit duration. This result is robust to shorter and longer tenure before entering unemployment. The non-negative effect on the jobless hazard is primarily due to a small difference in maximum duration between the treated group and the control group. In addition, workers with firm-specificity are likely to take any job in difficult position. Since the disincentive effects of UI benefit is weaker among UI recipients with firmspecific human capital, the results suggest that extending $\mathrm{UI}$ benefit of prime-age job-seekers with longer tenure at previous job is an effective tool to enhance welfare.

JEL Classification: J64, J65, J68

Keywords: maximum benefit durations, unemployment hazard, administrative data

Corresponding author:

Tomohiro Machikita

Institute of Developing Economies (IDE)

3-2-2, Mihama, Wakaba, Chiba, 2618545

Japan

E-mail: tomohiro_machikita@ide.go.jp

\footnotetext{
${ }^{*}$ We appreciate Ministry of Health, Labor, and Welfare (MHLW) and the Japan Institute for Labor and Public Training (JILPT) for allowing us to access Japanese administrative data. We are particularly grateful to the inputs from Yoko Asuyama, Hidehiko Ichimura, Seiro Ito, Hisaki Kono, Kazushi Takahashi, Kazunari Tsukada, Makoto Watanabe, Mariko Watanabe, Ken Yamada, and the participants of the Asian Meeting of Econometric Society in Delhi, December 2012. The authors receive Grant-in-Aid for Scientific research by the Ministry of Education, Culture, Sports, Science and Technology (MEXT) of the Japanese Government and Grant-in-Aid for Osaka University Global Centers of Excellent Program by MEXT.
} 


\section{Introduction}

There have been many important empirical researches on estimating the impact of the UI system on unemployment duration in the U.S. and Europe. Earlier evidence from the U.S. showed that extended unemployment benefits lead to longer unemployment duration. Moffit (1990), Meyer (1990), Katz and Meyer (1990), and Card and Levine (2000) focused on survey data for unemployed job-seekers to estimate the elasticity of maximum benefit duration and concluded that extended unemployment duration has a disincentive effect on exits from unemployment in the U.S. Meanwhile, Meyer (1995) and Krueger and Meyer (2002) provided good summaries of the U.S. evidence. Most recently, Landais, Michaillat, and Saez (2010) and Kroft and Notowidigdo (2011) examined how the disincentive effect on exits from unemployment differ between the period when returns to searching are high (booms) and the period when returns to searching are low (recessions). Rothstein (2011) examined this question further by utilizing the unprecedented huge extension of UI benefit duration (up to 99 weeks) and found that the UI extension had a significant but small negative effect on exits from unemployment. Farber and Valletta (2013) also investigated the same question by exploiting the timing and size variation of extended unemployment benefits across states. They found that (1) extended UI benefits cause a small but significant reduction in the unemployment hazard rate and a small increase in the expected duration of unemployment and (2) unemployment hazard and duration are primarily due to a reduction in exits from the labor force rather than a decrease in the job finding rate.

Empirical investigations have continued by using European administrative datasets covering all or a large proportion of UI recipients. In Sweden, Carling, Edin, Harkman, and Holmlund (1996) and Carling, Holmlund, and Vejsiu (2001) also found that longer benefit duration causes longer jobless duration. In Norway, Røed and Zhao (2003) focused on variations in unemployment compensation. They found that a marginal increase in UI compensation reduces the probability of exiting from unemployment. In the Netherlands, Abbring, van den Berg, and van Ours (2005) established a model of job searching with sanctions and found that punitive benefits lead to an increase in the re-employment rate. In Austria, Winter-Ebmer (1998), van Lalive and Zweimuller (2004), Lalive, van Ours and Zweimuller (2006), and van Ours and Vodopivec (2006) found that a longer maximum duration of unemployment benefits lowers the probability of leaving unemployment. In Germany, Schmieder, von Wachter, and Bender (2012) also confirmed, by using the age threshold of benefit duration of over 20 years, that there are nonemployment effects of a marginal increase in extended benefits. Previous research concluded that longer UI 
benefits also have a substantial disincentive effect on exit from unemployment in Europe. Tatsiramos and van Ours (2012) thoroughly surveyed the empirical and theoretical literature on the impacts of benefit duration on unemployment spells.

Lalive (2007, 2008), Caliendo, Tatsiramos, and Uhlendorff (2012), and Schmieder, Wachter, and Bender (2012) presented precise estimates of the impacts of extended benefit duration on unemployment spells focusing on the sharp discontinuity around the age threshold. However, we need to investigate other exogenous sources of variations in unemployment benefit duration to reduce the impact of age difference. The concept of this paper is simple. The age threshold and the reason for unemployment are the main sources of independent variations in maximum benefit duration. These two particular features of the Japanese UI system create four groups of workers: (1) job-seekers who lost their job due to an involuntary reason at the age of 45; (2) job-seekers who lost their job due to an involuntary reason but fail the age requirement; (3) job-seekers who leave their job voluntarily at the age of 45 ; (4) job-seekers who leave their job voluntarily under the age of 45 . The third and fourth groups have the same duration of maximum benefit within tenure of the previous job. Since the effect of the increase in maximum benefit duration on jobless duration depends on the size of the increase, this paper compares the treatment effects of the four groups for shorter tenure at the pre-unemployment job with the treatment effects of the four groups for longer tenure at the pre-unemployment job to check the robustness of our identification strategy.

To conduct the empirical analysis, we use large-scale administrative data with the unique institutional feature of the maximum duration of unemployment benefits in Japan. The sample is the universe of data from Japanese government sources. The system in Japan records day-to-day longitudinal information on the date of leaving the previous job, the date of starting job searching, the date of returning to employment, and the date when unemployment benefits cease. To be more precise, we restrict the sample to the 14,057 Japanese UI recipients in the age range of 44 to 46 who entered unemployment in August 2005 when the UI eligibility rules and business cycle (labor demand or establishment closures) were stable. This narrow age bandwidth around the age discontinuity can provide more precise estimates of the effects of extended unemployment benefits. This paper applies the difference-in-differences approach to the narrow age bandwidth which Lalive (2007, 2008), Caliendo, Tatsiramos, and Uhlendorff (2012), and Schmieder, Wachter, and Bender (2012) recently presented using a regression discontinuity design approach. Among the restricted sample of job-seekers aged 44 to 46 , there is a sharp discontinuity of the maximum duration of benefits for job-seekers with similar characteristics. Since 
involuntary job-leavers due to plant closure at the age of 45 cannot precisely manipulate these "treatment assignment variables", this strategy allows us to identify the exact effects of the extended maximum benefit duration on unemployment spells among unemployed job-seekers of the same age.

The results suggest that the duration of unemployment is not prolonged among jobseekers who left their job involuntarily at more than 45 years of age. Put simply, extended maximum unemployment benefits do not prolong unemployment spells. Prime-age displaced job-seekers with longer maximum benefit duration are not jobless for longer than their counterparts with shorter maximum benefit duration. The extended UI benefits in Japan are too small to make a significant difference in unemployment spells between treated and controls. Furthermore, workers with longer tenure at previous job are likely to take any job in difficult position because they have more firm-specific human capital. Since the disincentive effects of UI benefit is weaker among UI recipients with longer tenure at previous job, the results suggest that extending UI benefit for job-seekers is an effective tool to enhance welfare around this age.

The next section explains the research design and identification strategy utilizing the background of the unemployment benefits schedule for displaced workers in Japan. Section 3 introduces the data, Section 4 shows empirical results, and Section 5 concludes with a discussion and a summary of the results.

\section{Institutions and research design}

\subsection{Japanese UI system and sources of variations in benefit durations}

Unemployment benefits are available for the displaced in Japan. The Japanese UI system has many common features with the systems of other countries studied by previous researchers. Nevertheless, although the UI system in Japan shares a common institutional setting with Austria, Germany, and the US, it has several unique features that generate exogenous variations in unemployment benefit. In Japan, the UI system does not vary with the business cycle. Unemployment benefit payments usually cover $50 \%$ to $80 \%$ of the wage at the previous job. The potential duration of unemployment benefits is 90 to 360 days; the maximum duration is 360 days. Once the cumulative unemployment spells after leaving the previous job exceed 360 days, the unemployed cannot receive benefits. The benefit replacement rate is not low, and the maximum benefit duration is short. This is a major difference compared to other OECD countries which have a higher replacement rate during one year and move to a lower replacement rate for several years. Unemployed 
job-seekers in Japan must go to public employment service office every four weeks and receive advice. The voluntarily unemployed cannot receive unemployment benefits until they have searched for a job for three months since leaving the previous job. The UI system has a qualifying period for eligibility: about 6 months of employment in the last one year for the involuntarily unemployed and 1 year of employment in the last one year for the voluntarily unemployed. The voluntarily unemployed have a waiting period of 90 days to be eligible.

There are two particular features of the Japanese unemployment benefit system that relates to the setting of this paper. First, the maximum duration of unemployment benefit payment crucially depends on the reason for leaving the previous job: whether the person quit voluntarily, or was made redundant for involuntary reasons. Involuntary reasons include closure of the establishment, relocation of the establishment, and being dismissed due to reasons of the establishment. These are considered not to be the worker's own reasons. This raises an exogenous source of the maximum duration of unemployment benefits. Second, the maximum duration of unemployment benefit payment depends not only on the age of the job-seekers who left the previous job but also the tenure at the previous job. However, the maximum duration of unemployment benefits is the same among voluntary job-leavers. There is no discrimination by age among voluntary jobleavers; there is only a difference in the maximum duration of unemployment benefits depending on job tenure at the previous job. ${ }^{1}$

On the other hand, the maximum duration of unemployment benefits greatly differs among involuntary job-seekers within and across age groups. There are five age groups and five job tenure groups respectively, totaling 25 categories. The most notable examples are concentrated around the age of 45 . Benefit duration for the age group 35-44 is 90 days if the unemployed had been employed for 1 to 4 years at the previous job prior to the current spell, yet 180 days for the age group 45-60 if employed for the same 1 to 4 years at the previous job. Previous job tenure also changes the maximum duration of unemployment benefits as follows. The unemployed who had been employed for 5 to 9 years at the previous job prior to the current spell receive benefits for 180 days if their age group is 35-44, yet they receive benefits for 240 days if their age group is 45-60. Analogously, the unemployed who had been employed for 10 to 19 years at the previous

\footnotetext{
${ }^{1}$ In our sample, there are three types of duration of unemployment benefits for voluntary job-leavers by category of job tenure at the previous job: (1) 1-4 years; (2) 5-9 years; (3) 10-19 years. Benefit duration for voluntary job-leavers is 90 days if the unemployed had been employed for 1 to 4 years prior to the current spell, 120 days if employed for 5 to 9 years prior to the current spell, and 120 days if employed for 10-19 years prior to the current spell. Voluntary job-leavers who had job tenure of less than 1 year cannot receive unemployment benefits.
} 
job prior to the current spell receive benefits for 240 days if their age group is 35-44, yet they receive benefits for 270 days if their age group is $45-60$. Thus, a sharp discontinuity exists around the age of 45 for involuntary job-seekers.

Although these characteristics may not be unique compared to European countries, the schedule of Japanese unemployment benefits has a large discrepancy between involuntary and voluntary job-seekers as shown in Table 1. In turn, the Japanese UI system provides an opportunity to examine the effect of extended benefit duration on jobless duration among the unemployed of the same age by using the sharp discontinuity in potential UI duration which is a function of the reason for displacement. We implement a RD design separately for shorter and longer pre-displacement tenure. We utilize this variation and exogenous source of maximum duration of unemployment benefit. ${ }^{2}$

$$
==\text { Table } 1==
$$

\subsection{A local quasi-experiment}

To keep the demand effect which was shown in the previous section, this paper restricts the analysis sample to those aged close to 45 , following an identification strategy of a regression discontinuity design. The exact age of leaving the previous job is calculated on the basis of the date when the unemployed left the previous job and their birth year and month reported in the data which were collected during August 2005. We restrict our attention to individuals aged 44 to 46 at the beginning of unemployment spells in August 2005. Even though the number of samples is reduced, this empirical design enables us to focus on the sharp discontinuities of maximum duration of unemployment benefits for individuals aged around 45 years old who have similar characteristics. It is a local randomized experiment which has mild identification assumptions. The influence of (age-specific) demand for workers is controlled for by an assumption that it equally affects the unemployed just below or above the age threshold of 45 . We can focus on the impacts of longer maximum duration of benefit on unemployment spells through supply behavior.

The identification strategy is clear and simple. Maximum benefit durations differ with pre-displacement tenure within the same age. This depends on the assumption that the

\footnotetext{
${ }^{2}$ In the United States, there are no strict age thresholds in the UI system, while in Austria and Germany the UI system is a function of the exact age at job displacement. In particular, strict age thresholds in the UI system in Austria and Germany provide an opportunity to implement a regression discontinuity (RD) design to estimate the effects of extended unemployment insurance on unemployment duration at the age threshold. See Schmieder, von Wachter, and Bender (2012) for the case of Germany.
} 
maximum benefit duration for displaced UI recipients due to involuntary reason at the age of 45 is not correlated with unobserved characteristics of workers that affect their duration of unemployment. To be more precise, we assume that plant or establishment closure is a random event for workers aged around 45. That is, workers have been exogenously removed from their job and displaced workers cannot manipulate their age at job loss due to closure of the establishment, relocation of the establishment, and being dismissed due to reasons of the establishment. In the Japanese UI system, displaced workers facing such exogenous reasons at the age of 45 can receive longer unemployment benefits compared to UI recipients who are exogenously displaced at age 44 and the voluntarily unemployed at age 44 or 45 . Since the displaced workers cannot manipulate their age at firm closure, the difference between the expected duration of unemployment among UI recipients by plant or establishment closure at the age of 45 and those aged 44 corresponds to the increase in maximum benefit duration and the role of age in the labor market. To identify the impact of the increase in maximum benefit duration on jobless duration among the pool of displaced UI recipients aged 45 and those aged 44, we can remove the influence of age from expected jobless duration by using the sample of those who quit at the age of 45 and at the age of 44 . These create the following four categories of maximum benefit duration: the first group who experienced displacement due to exogenous reasons at the age of 45 (180-270 days in this sample); the second group who experienced displacement due to exogenous reasons at the age of 44 (90-240 days in this sample); the third group who left their previous job voluntarily at the age of 45 (90-120 days in this sample); the fourth group who left their previous job voluntarily at the age of 44 (90-120 days in this sample).

To be specific, there are three sharp tenure thresholds in the potential benefit duration: 5 years' experience, 10 years' experience, and 20 years' experience at the preunemployment job. Depending on the tenure at the age of 45 , the potential UI duration could increase from 90 to 180 days ( 1 to 4 years' tenure), 180 to 240 days (5 to 9 years' tenure), or 240 to 270 days (10 to 19 years' tenure). We compare the sample of those involuntarily becoming unemployed for reasons of the establishment at the age of 45 with those voluntarily becoming unemployed at the age of 45 in August 2005. ${ }^{3}$

\footnotetext{
${ }^{3}$ In the Japanese UI system, displaced workers with longer job tenure are eligible for longer benefit durations. Firm layoffs/recalls are not common and it is costly for firms to fire workers in Japan, so firms may have an incentive to fire workers who are eligible for longer benefit durations. If firms are likely to selectively fire less-able workers eligible for longer benefit durations, the average unobserved characteristics which influence jobless duration between the treated group and the control group could be biased. We also assess this concern to utilize the discontinuity in potential unemployment benefits between UI recipients with shorter and longer pre-displacement tenure at the age of 45 .
} 


\subsection{Difference-in-differences approach for narrowly defined age range}

We follow Caliendo, Tatsiramos, and Uhlendorff (2012) to show our identification strategy. It gives a credible result. Japanese legislation for maximum unemployment benefits has sharp discontinuities with respect to three types of individual characteristic: the reason for displacement from the previous job, age at displacement, and job tenure at the previous job. First, maximum unemployment benefits have sharp discontinuities with respect to the reason for displacement from the previous job. Let us assume that $R_{i}$ describes a binary treatment variable indicating whether unemployed job-seekers have been displaced due to voluntary reasons $\left(R_{i}=0\right)$ or involuntary reasons such as plant or establishment closure $\left(R_{i}=1\right)$. Under Japanese legislation, the maximum benefit duration $B$ is longer for the involuntarily unemployed than the voluntarily unemployed.

Second, maximum unemployment benefits also show sharp discontinuities with respect to age. $A_{i}$ describes a binary treatment variable indicating whether individuals are below $\left(A_{i}=0\right)$ or above $\left(A_{i}=1\right)$ the age threshold at the time of becoming unemployed from the previous job. The threshold we are interested in corresponds to age 45. Under Japanese legislation, the maximum benefit duration $B$ is longer only for age 45 or more workers who are displaced from their previous job due to involuntary reasons. The treatment assignment $D_{i}$ is a deterministic function of the age below and above the threshold upon leaving the previous job due to involuntary reasons such that $D_{i}=\mathbf{1}\left\{R_{i}=1 \cap A_{i}=1\right\}$. If unemployed job-seekers were above the threshold upon leaving the previous job due to plant closure for example, they receive maximum benefits for longer. We seek to estimate the impact of assignment variable $D_{i}$ on the probability of leaving unemployment. The main variable of interest is the assignment variable $D_{i}$ denoting whether unemployed job-seekers were displaced due to exogenous reasons when they were more than 45 years old. It is a local randomized experiment.

One concern about our identification strategy is that an increase in UI benefits can also have an impact on unemployment rate through a firm's decision to lay off specific types of workers, but this is known to be costly in Japan. Other potential concern is that job-seekers will postpone entry into unemployment and the impacts of assignment variable $D_{i}$ with its potential bias. However, Japanese legislation does not consider age

among the voluntarily unemployed, although there are some differences with respect to job tenure at the previous job: unemployed job-seekers who had longer job tenure at the previous job can receive maximum benefits for longer. To deal with such strategic behavior and unobserved heterogeneity, we will estimate the causal impacts of longer maximum benefit duration by job tenure at the previous job. After showing empirical 
results, we also use other measure of unemployment durations for robustness checks. Table 2 summarizes the maximum days of benefit durations by age at job loss, reason of separation, and pre-displacement tenure around age 45. Our interests are three categories of pre-displacement tenure: (1) 1-4 years; (2) 5-9 years; (3) 10-19 years.

$$
==\text { Table } 2==
$$

We estimate a hazard model for the transition rate from unemployment to employment. The unemployment hazard rate $\lambda$ can be written as follows:

$$
\lambda=\lambda_{0} \exp \left(\alpha R_{i}+\beta A_{i}+\gamma D_{i}+X_{i}^{\prime} \delta+u_{i}\right)
$$

where $\lambda_{0}$ denotes the common baseline hazard rate and the parameter $\gamma$ captures the impact of the assignment variable $D_{i}$ which increases in the maximum benefit duration on the hazard rate from unemployment to employment. The parameter $\alpha$ captures the effects of the assignment variable involuntary or voluntary reason for displacement on the hazard rate from unemployment to employment. The parameter $\beta$ captures the effects of the assignment variable age below or above the threshold on the hazard rate from unemployment to employment. In addition, we include observable and unobservable individual characteristics $X_{i}$ and $u_{i}$ to explain the hazard from unemployment to employment. Observed age difference is already captured by $\beta$.

\section{The Data}

\subsection{Matching two administrative datasets}

This paper combines two administrative datasets for the empirical analysis: data on individuals entering unemployment from a job in August 2005, and data on unemployment insurance (Koyo Hoken Gyomu Toukei in Japanese) which includes all individuals who have registered with the UI scheme and hold UI identification numbers. The administrative data does not include information about individuals who do not have UI identification numbers such as the self-employed, housewives, and part-time workers who worked less than 20 hours a week. In addition, we exclude the following types of individuals among all those eligible for UI: (1) Individuals who are over 65 years old, (2) Seasonal workers, (3) Day workers, and (4) Unemployed job-seekers who remain unemployed for more than 365 days. The administrative data from the Japanese UI system cannot trace job-seekers who get a position without UI. That is, we cannot observe the exits from unemployment 
if job-seekers get a position with a firm that is not involved in the Japanese UI system. This is the disadvantage of depending on government administrative data.

Since administrative data on unemployment is collected through public employment service offices, administrative data on UI includes not only information on the date of leaving the previous job but also information on the date of starting job-seeking activities through public agencies. We have combined the above government dataset on unemployment insurance with a government dataset on job findings (Shokugyo Antei Gyomu Toukei in Japanese) to construct two types of unemployment spell before finding a new job: (1) unemployment spells between the date of registering to start job-seeking and the date of finding a new job, and (2) unemployment spells between the date of leaving the previous job and the date of finding a new job. This dataset tracks the job search process from the date when a job seeker registered at his/her local employment service office to the date when he/she found a job, or the last date in the observed interval (13 July 2006).

We can merge both datasets to make matched dataset because these include a common identification (ID) number for each job-seeker. ${ }^{4}$ The use of these administrative data has three apparent advantages. First, our matched dataset has exact days of leaving the previous job, starting job searching, and re-employment only if individuals exit from unemployment. This provides us with exact unemployment spells and job search spells. Second, these administrative data are nationally representative and compulsorily surveyed for the recipients of unemployment insurance, that is, respondents are not selfselected, unlike in general survey data. Third, the data include all the unemployed who lost their job during the same month in the same year throughout the country. Thus, we can control for macroeconomic conditions in the initial stage of unemployment. ${ }^{5}$

\subsection{Characteristics of Japanese UI recipients}

Table 3 describes the main characteristics of Japanese unemployed job-seekers with UI. To see big picture here, we do not restrict the sample to those who lost their job at age around 45. There are wide variations in market tightness across regions in the country. This is one of the main characteristics of the Japanese labor market, which means that unemployment

\footnotetext{
${ }^{4}$ The matched data leaves us with only job seekers who are eligible to receive unemployment benefits during their job search and have registered at the public employment service office.

${ }^{5}$ This time was not period special regarding the generation of displaced workers. We have no evidence that the frequency of firm closures was especially high in August 2005. We checked the bankruptcy information provided by Teikoku Databank in Japan. In August 2005, the number of bankruptcies in Japan was 754. The numbers were 794 and 675 in June and July 2005, respectively, and were 671 and 825 in September and October 2005, respectively. Since the number of bankruptcies moves cyclically and the number of bankruptcies in Japan in August 2006 was 774, it is safe to say that our sample does not reflect a special period of changes in the labor market.
} 
spells and re-employment rates differ significantly across local labor markets. Public employment service offices in Japan, of which there were almost 600 in 2005, collect the local ratio of job openings to applicants. We summarize the maximum duration of benefits (days), unemployment spells (days), ratio of re-employment, age of unemployed at displacement, pre-displacement job tenure (days), and years of schooling by quintile of the ratio of job openings to applicants when the unemployed left their previous job.

$$
==\text { Table } 3==
$$

First, the maximum duration of unemployment benefits is slightly longer in a thick market. This is natural, since the maximum duration of unemployment benefits should be determined by age and job tenure. There are several features between thick and tight markets. Second, the local labor market with the top 5\% ratio of job openings to applicants experienced 74 to 75 days longer of unemployment spells than the local labor market with the bottom 5\% ratio of job openings to applicants (274 days vs. 199.6 days on average). This is true if we utilize another measure of market tightness, that is, the ratio of job openings to applicants when the unemployed started to look for a new job. Third, the average age is older among unemployed leavers in a booming local labor market (age 39) than among the unemployed in the local labor market with the bottom $5 \%$ ratio of job openings to applicants (age 36). Fourth, the mean and standard deviation of job tenure at the previous job are longer in a thick market (2505 days or nearly 6.9 years for a region in the top $5 \%$ vs. 1595 days or nearly 4.4 years for a region in the bottom $5 \%$ ).

\section{Results}

\subsection{Baseline result}

To assess more precisely the impacts of maximum benefit duration on jobless duration, we restrict the sample to those who lost their job at age around 45 from August 1 to 31, 2005. The age bandwidth around the age of 45 is two years: 44,45 , and 46 years old at job loss. UI recipients of age 45 or 46 at job loss due to involuntary reason can receive benefits for the longest among the pool of UI recipients. The resulting data contain information on the reason for leaving the previous job and age upon entering unemployment for 14057 individuals entering unemployment in August 2005: (1) 5675 individuals with tenure from 1 to 4 years prior to displacement, (2) 6053 individuals with tenure from 5 to 9 years, and (3) 2329 individuals with tenure from 10 to 19 years. The different tenure 
categories give different lengths of unemployment benefit. Among workers with the same tenure category prior to displacement, maximum benefit durations differ with age upon job loss and the reason for job loss. The data also contain individual characteristics which can be used to determine unemployment hazard such as gender, marital status, years of schooling, monthly wage at the previous job, and the number of job offers to job-applicants to capture labor market tightness.

An econometric problem arises if age leads to sample attrition, but our narrow bandwidth around the age of 45 ensures that any sample attrition happens randomly. Sample attrition is unlikely to happen when we look at the age range of 44-46. To estimate the effect of extended unemployment benefit duration on unemployment spells, we specify the hazard model as a function of individual characteristics and eligibility for the program: age 45 dummy variable indicating whether individual $i$ was aged 45 when they left their previous job, and involuntary job loss dummy variable indicating whether individual $i$ was displaced due to firm closure. To ensure exact matching when comparing workers, we restrict the sample to those aged 44-46 only and the results based on a hazard model that identifies the treatment effect of extending unemployment benefits in age on both sides of the threshold (45 years old).

Columns 1 to 3 in Table 4 show that unemployment spells start from the date of registering to start job-seeking. This is the data they first take up UI benefits at local agencies and register there to look for a job. The empirical analysis here also provides more detailed specification of the time-varying effect of the termination period by using the dummy variable if the UI is expired within 14 days. Thus, we can carefully show the treatment effect of extending unemployment benefits taking account of UI exhaustion splines as time varying variables. Columns 4 to 6 in Table 4 do not take into account of the time-varying effects. We focus on Columns 1 to 3 in Table 4 for explanation.

We are mainly interested in interaction terms between the variable of involuntary job leaving and the dummy variable of 45 years old upon entering unemployment. Involuntary job-leavers aged 45 can receive 180 days of unemployment benefits while involuntary job-leavers aged 44 can receive 90 days. The latter individuals who have not yet reached the age threshold of 45 years cannot receive any such "bonus" compared to the maximum duration of unemployment benefits for voluntary job-leavers (90 days). The estimated coefficient of interaction terms signifies the treatment effect in the unemployment hazard model. Overall, the treatment effect of column 1 of Table 2 do not provide significant or strong evidence that the involuntarily unemployed who have reached the age threshold of 45 years remain unemployed. This is also true for the case when we do not allow effect 
of UI vary overtime (column 4 of Table 4 ).

Column 2 of Table 4 shows the effect of extended benefits on jobless duration for individuals with job tenure of 5-9 years at the previous job. There is a difference of 60 days in the maximum duration of unemployment benefits between individuals who had reached the age threshold of 45 years (treatment group, 240 days) and individuals who had not yet reached the age threshold of 45 years (control group, 180 days) among the sample. The individuals who had not yet reached the age threshold could receive a "bonus" of 90 days compared to the maximum duration of unemployment benefits for voluntary job-leavers (90 days). The main interest here is still the treatment effect, that is, interaction terms between the dummy variable of involuntary unemployment and the dummy variable of the age threshold of 45 years. The treatment effect in Column 2 of Table 4 are not negative. This holds for the case when we do not allow effect of UI vary overtime (column 5 of Table 4).

Column 3 of Table 4 shows the effect of extended benefits on jobless duration for individuals with job tenure of 10-19 years at the previous job. There is a difference of 30 days in the maximum duration of unemployment benefits between individuals who had reached the age threshold of 45 years (treatment group, maximum duration of benefit is 270 days) and individuals who had not yet reached the age threshold of 45 years (control group, maximum duration of benefit is 240 days) among the sample. The individuals who had not yet reached the age threshold of 45 years could receive a "bonus" of 120 days compared to the maximum duration of unemployment benefits for voluntary job-leavers (120 days). The treatment effect (i.e., interaction terms between the dummy variable of involuntary unemployment and the dummy variable of the age threshold of 45 years) in column 3 of Table 4 suggest that extended benefits have positive effects on unemployment hazard. The treatment effect, that is, interaction term is positive but not statistically significant at $10 \%$. This means that there is disincentive effects for treatment group (individuals who have reached 45 years old with job tenure of 10-19 years) compared to the control. This holds for individuals when we do not allow effect of UI vary overtime (column 6 of Table 4).

$$
==\text { Table } 4==
$$

Finally, we compare columns 1 and 2 with column 3 of Table 4 to understand how the differences in maximum benefit duration between the treated group and the control group affect the impact of extended maximum duration of unemployment benefits on the 
hazard rate from unemployment to employment. The coefficient of Treated in Column 1 reflects the 90-day difference in maximum benefit duration between the treated group with 180 days and the control group with 90 days. The coefficient of Treated in Column 2 also reflects the 60-day difference in maximum benefit duration between the treated group with 240 days and the control group with 180 days. In addition, the coefficient of Treated in Column 3 reflects the 30-day difference in maximum benefit duration between the treated group with 270 days and the control group with 240 days. The estimated hazard rate is lower for the treated group who are entitled to a larger difference in maximum benefit duration (as depicted in Column 1 of Table 4) than the treated group who are entitled to a smaller difference in maximum benefit duration (Column 3 of Table 4).

In sum, this paper exploits three types of discontinuity in the maximum benefit duration in Japan, that is, a change specific to age, a change specific to the reason for displacement, and a change specific to the pre-displacement tenure. For involuntarily displaced workers aged 45 or more, the maximum benefit durations are 30 to 90 days longer than those of involuntarily displaced workers aged 44 or less, and 90 to 150 days longer than those of workers who quit voluntarily. Pre-displacement tenure also changes these maximum benefit durations. We use these discontinuities with age at displacement and reason for displacement in UI entitlements to estimate the effect of maximum benefit duration extension on the job-finding hazard. We use the Japanese government data for workers aged 44 to 46 who lost their job during August 1 to 31, 2005. From the estimates it appears that the job-finding hazard does not reduce for any pre-displacement tenure groups. This means that the duration of unemployment for those with longer maximum benefit duration was not prolonged at least for job-seekers around 45 years old. The difference in maximum benefit duration in Japan of just one to three months is not big enough to reduce the unemployment hazard around this age. The difference between this paper and previous studies is attributed to the difference between changes in maximum benefit duration in Japan and Europe. Japan does not have a bigger extension in maximum benefit duration for treated than in Europe. It is worth noting that in Japan, longer unemployment duration is sensitive to changes in maximum benefit duration. Furthermore, we cannot observe the disincentive effects of extended unemployment benefit for UI recipients who have longer pre-displacement tenure.

\subsection{Robustness checks: the results for alternative duration}

Empirical results suggest that longer UI benefits are not associated with much lower exit rates for job-seekers around 45 years old. We also found that this argument is robust 
to tenure of pre-displacement job. One concern is the institutional setting that Japanese UI recipients are not able to actually receive benefits without first registering with the local public employment service office. This means that the date on which an individual lost his or her last job does not exactly correspond with the date on which he or she registered as an unemployed job-seeker at the local employment office. Since there could be some time between displacement and the first take-up of UI benefits, we have to take into account the fact that UI recipients can start looking for a job before taking up UI benefits in the baseline results. We must assess whether the baseline results are robust to the definition of unemployment spells. To see whether our main result is sensitive to time until claiming UI, Table 5 presents the results based on the date when unemployed left a previous job.

Table 5 shows that the treatment group does not experience a lower probability of leaving unemployment if we use the date when they first take up UI benefits and start to look for a new job at local UI agencies as the starting date of unemployment spells. Column 1 of Table 5 reports the hazard estimates for unemployed job-seekers who have 1-4 years' experience at their pre-displacement job if the unemployment spell starts from the date of first taking up UI benefits and starting to look for a new job at local UI agencies. Column 1 of Table 5 shows that the hazard estimate of the treatment group is not significantly negative. This means that UI recipients who lost their job involuntarily at the age of 45 do not experience longer joblessness than displaced UI recipients who lost their job exogenously at the age of 44 among the sample with shorter job tenure. Columns 2 and 3 of Table 5 present the hazard estimates of the treatment group for the samples with job tenure of 5-9 years and 10-19 years. Among the sample who have longer pre-displacement tenure, the hazard estimates of the treatment groups are not significant and negative. The treatment groups do not experience longer joblessness if their unemployment spell starts from the date of first taking up UI benefits and starting to look for a new job at local UI agencies. In addition, the coefficients of individual characteristics in Table 5 and the log likelihood are quite similar to those in Table 4 . These results suggest that the main results of this paper (Table 4) are robust to the definition of the starting point of unemployment spells. These results are true if we do not take into account of the time-varying effects in Columns 4 to 6 in Table 5.

$$
==\text { Table } 5==
$$

In sum, we find that the disincentive effects of UI duration are smaller among invol- 
untary job-leavers who receive maximum benefits for longer in all cases. This suggests that those who lose their job against their will may have a stronger preference for reemployment, and therefore, they are eager to exit from unemployment as soon as possible, despite the generous provision of unemployment benefits compared to job-seekers who quit their job voluntarily. We do not observe that a lower exit rate from unemployment is associated with longer maximum benefit duration. The effect of the extended benefit duration on the exit rate from unemployment is not negative, is small, and is not significantly different from zero controlling for the sharp discontinuities within the same age group. This argument is robust to pre-displacement tenure. The particular features of the UI system create independent and exogenous variations for UI recipients of the same age. This clean identification strategy allows us to investigate the impact of extended benefit duration on jobless duration within the same age group while we relax the assumption about age in the previous regression discontinuity (RD) design approach. The finding that sharp discontinuities in the duration of benefits do not lead to longer jobless duration in Japan means that changing the benefit duration is an ineffective tool to influence incentives for Japanese prime-age UI recipients around 45 years old.

\section{Conclusion}

This paper studied how changes in extended unemployment insurance (UI) benefit affect the jobless duration by using a quasi-experimental setting of maximum benefit duration. The paper investigated this question by exploiting not only strict age thresholds at job displacement but also the pre-displacement tenure and the reason for separation from the previous job in the Japanese UI system, which affect the worker's maximum potential duration of UI benefits. The UI system in Japan also allows us to relax the identification assumption of previous regression discontinuity (RD) design approaches which assumed that predetermined individual characteristics change little at the age thresholds. We can also relax another RD assumption that the density of unemployment spells around the age thresholds is smooth. Since the Japanese UI system has sharp discontinuities in potential UI durations for the involuntarily displaced and voluntary job-leavers at the age of 45 , we can estimate the impacts of extended UI benefits while controlling for age. In addition, the Japanese UI system also has sharp discontinuities in potential UI durations for the unemployed between longer or shorter pre-displacement tenure at the age of 45 . Among these three types of threshold in the Japanese UI system, unemployed job-seekers

displaced due to exogenous reasons (such as establishment closure) at the age threshold of 45 who have longer pre-displacement tenure receive maximum benefits for longer. 
We applied the difference-in-differences approach to a large Japanese government dataset of workers aged 44 to 46 who became unemployed between August 1 and 31, 2005. Such narrowly defined age range and sample provides more accurate estimates by reducing unobserved heterogeneity. The maximum benefit duration for UI recipients displaced due to plant or establishment closure at the age of 45 is not correlated with unobserved characteristics of workers that affect their unemployment hazard rate. Empirical findings show no evidence that extended benefit durations lead to longer unemployment spells for the treatment group aged 45 and 46. That is, the duration of unemployment is not prolonged among job-seekers, possibly because the duration for which they are entitled to receive benefits is not much longer than that of the control group aged 44 . This result is robust to pre-displacement tenure, suggesting that longer benefits durations are not associated with much lower exit rates for all job-seekers who have shorter and longer tenures. Since Japan has an underprivileged extension in maximum benefit duration for the treated than in Europe, the disincentive effect of extended benefit durations is weak among prime-age job-seekers. Therefore, small changes in maximum benefit durations are not an effective policy tool for reducing jobless duration among prime-age job-seekers. This paper concludes that extending UI benefit for job-seekers with longer tenure at previous job is an effective tool to enhance welfare because the disincentive effects of UI benefit is weaker among UI recipients with firm-specific human capital. 


\section{References}

Abbring, Jaap H., Gerald J. van den Berg, and Jan C. van Ours (2005) "The effect of unemployment insurance sanctions on the transition rate from unemployment to employment," Economic Journal, 115: 602-630.

Caliendo, Marco, Konstantinos Tatsiramos, and Arne Uhlendorff (2012) "Benefit duration, unemployment duration, and job match quality: a regression discontinuity approach," Journal of Applied Econometrics, 28: 604-627.

Card, David and Phillip B. Levine (2000) "Extended benefits and the duration of UI spells: evidence from the New Jersey extended benefit program," Journal of Public Economics, 78: 107-138.

Carling, Kenneth, Per-Anders Edin, and Anders Harkman, and Bertil Holmlund (1996) "Unemployment duration, unemployment benefits, and labor market programs in Sweden," Journal of Public Economics, 59: 313-334.

Carling, Kenneth, Bertil Holmlund, and Altin Vejsiu (2001) "Do benefit cuts boost job finding? Swedish evidence from the 1990s," Economic Journal, 111: 766-790.

Farber, Henry S., and Robert G. Valletta (2013) "Do Extended Unemployment Benefits Lengthen Unemployment Spells? Evidence from Recent Cycles in the U.S. Labor Market," Working Paper No. 573 Princeton University, Industrial Relations Section.

Katz, Lawrence F., and Bruce D. Meyer (1990) "The impact of the potential duration of unemployment benefit on the duration of unemployment," Journal of Public Economics, 41: 45-72.

Kroft, Kory, and Matthew J. Notowidigdo. (2011) "Should Unemployment Insurance Vary with the Local Unemployment Rate? Theory and Evidence." Working paper No. 17173, National Bureau of Economic Research, June 2011.

Krueger, Alan B. and Bruce D. Meyer (2002) "Labor supply effects of social insurance," Handbook of Public Economics, Chapter 33, Volume 4, edited by A. J. Auerbach and M. Feldstein: 2327-2392. 
Lalive, Rafael (2007) “Unemployment benefits, unemployment duration, and post-unemployment jobs: a regression discontinuity approach," American Economic Review Papers and Proceedings, 97(2): 108-112.

Lalive, Rafael (2008) "How do extended benefits affect unemployment duration? A regression discontinuity approach," Journal of Econometrics, 142: 785-802.

Lalive, Rafael, Jan C. van Ours and Josef Zweimuller (2006) "How changes in financial incentives affect the duration of unemployment?" Review of Economic Studies, 73: 10091038.

Lalive, Rafael and Josef Zweimuller (2004) "Benefit entitlement and unemployment duration: The role of policy endogeneity," Journal of Public Economics, 88: 2587-2616.

Landais, Camille, Pascal Michaillat, and Emmanuel Saez (2010) "Optimal Unemployment Insurance over the Business Cycle." NBER Working Paper 16526, November 2010.

Meyer, Bruce (1990) "Unemployment insurance and unemployment spells," Econometrica, 58: 757-782.

Meyer, Bruce (1995) “Lessons from the U.S. unemployment insurance experiments," Journal of Economic Literature, 33: 91-131.

Moffitt, Robert (1985) "Unemployment insurance and the distribution of unemployment spells," Journal of Econometrics, 28: 85-101.

Røed, Knut and Tao Zhang (2003) "Does unemployment compensation affect unemployment duration," Economic Journal, 113: 190-206.

Rothstein, Jesse (2011) "Unemployment Insurance and Job Search in the Great Recession," Brookings Papers on Economic Activity, 43(2): 143-213.

Schmieder, Johannes F., Till von Wachter, and Stefan Bender (2012) "The effects of extended unemployment insurance over the business cycle: evidence from regression 
discontinuity estimates over 20 years", Quarterly Journal of Economics, 127(2): 701-752.

Tatsiramos, Konstantinos and Jan C. van Ours (2012) "Labor market effects of unemployment insurance design," Journal of Economic Surveys, forthcoming.

van Ours, Jan C., and Milan Vodopivec (2006) "How shortening the potential duration of unemployment benefits affects the duration of unemployment: Evidence from a natural experiment," Journal of Labor Economics, 24: 351-378.

Winter-Ebmer, Rudolf (1998) "Potential unemployment benefit duration and spell length: Lessons from a quisi-experiment in Austria," Oxford Bulletin of Economics and Statistics, 60(1): 33-45. 
Table 1: Variation in maximum days of benefit by pre-displacement tenure

Job tenure (years) Less than 1 year $1-4$ years $5-9$ years $10-19$ years 20 years -

Involuntary unemployed

Age 60-64 90

Age 45-59 90

$\begin{array}{lllll}90 & 150 & 180 & 210 & 270\end{array}$

Age 35-44 90

$180 \quad 240 \quad 270 \quad 330$

Age 30-34

90

$90 \quad 180$

$240 \quad 270$

Less than age 30

90

$90 \quad 180$

$210 \quad$ NA

$90 \quad 120$

180

NA

Quits

All

90

90

120

120

150

Notes: NA means not applicable for unemployed job-seekers less than age 30 by definition.

Sources: Employment Security Bureau, Ministry of Health, Labour and Welfare. 
Table 2: Maximum days of benefits by age, reason of separation, and tenure

\begin{tabular}{lccc}
\hline Panel A: Pre-displacement tenure is 1 to 4 years & & \\
\hline$R=1$ (if exogenous separations), $R=0$ (if quits) & $R=1$ & $R=0$ & $\Delta R$ \\
\hline & & & \\
$A=1$ (if age 45 or 46 at displacement) & 90 & 90 & 90 \\
$A=0$ (if age 44 at displacement) & 90 & 90 & 0 \\
$\Delta A$ & 90 & 0 & \\
\hline
\end{tabular}

Panel B: Pre-displacement tenure is 5 to 9 years

$R=1$ (if exogenous separations), $R=0$ (if quits)

$R=1 \quad R=0 \Delta R$

$A=1$ (if age 45 or 46 at displacement) $\quad 240 \quad 120120$

$A=0$ (if age 44 at displacement) $\quad 180 \quad 120 \quad 60$

\begin{tabular}{lll}
$\Delta A$ & 60 & 0 \\
\hline
\end{tabular}

Panel C: Pre-displacement tenure is 10 to 19 years

$R=1$ (if exogenous separations), $R=0$ (if quits)

$R=1 \quad R=0 \Delta R$

$A=1$ (if age 45 or 46 at displacement) $\quad 270 \quad 120150$

$A=0$ (if age 44 at displacement) $\quad 240 \quad 120120$

$\begin{array}{lrr}\Delta A & 30 & 0\end{array}$

Notes: NA means not applicable for unemployed job-seekers less than age 30 by definition.

Sources: Employment Security Bureau, Ministry of Health, Labour and Welfare. 
Table 3: Summary Statistics by the Ratio of Job Openings to Applicants

\begin{tabular}{lcccccc}
\hline Variable & Bottom 5\% & $5-25 \%$ & $25-50 \%$ & $50-75 \%$ & $75-95 \%$ & Top 5\% \\
\hline Maximum duration of benefits (days) & 114.0 & 120.5 & 121.9 & 120.0 & 120.1 & 119.4 \\
& $(53.1)$ & $(58.6)$ & $(58.8)$ & $(56.8)$ & $(55.8)$ & $(54.8)$ \\
Unemployment spells (days) & 199.6 & 188.9 & 219.1 & 221.6 & 223.6 & 274.1 \\
& $(119.8)$ & $(118.4)$ & $(116.3)$ & $(118.0)$ & $(107.1)$ & $(96.6)$ \\
Ratio of re-employment & 0.618 & 0.654 & 0.532 & 0.501 & 0.573 & 0.253 \\
& $(0.486)$ & $(0.476)$ & $(0.499)$ & $(0.500)$ & $(0.495)$ & $(0.435)$ \\
Age of unemployed left a previous job & 36.6 & 38.3 & 39.1 & 39.0 & 39.2 & 39.3 \\
& $(12.2)$ & $(12.6)$ & $(12.8)$ & $(12.9)$ & $(12.9)$ & $(13.1)$ \\
Job tenure at previous job (days) & 1595.5 & 1911.4 & 2248.8 & 2283.6 & 2380.2 & 2505.9 \\
& $(2282.8)$ & $(2610.2)$ & $(2972.5)$ & $(3036.2)$ & $(3075.1)$ & $(3225.1)$ \\
Years of schooling & 12.3 & 12.5 & 12.8 & 12.9 & 12.9 & 13.1 \\
& $(1.8)$ & $(1.9)$ & $(2.0)$ & $(2.0)$ & $(2.1)$ & $(2.2)$
\end{tabular}

Notes: Standard deviations are in parentheses. The ratio of job openings to applicant is at the date when unemployed left a previous job.

Sources: Data on unemployment insurance (Koyo Hoken Gyomu Toukei) and data on job findings (Shokugyo Antei Gyomu Toukei). 
Table 4: Hazard Estimates of Leaving Unemployment for 44-46 Years Old

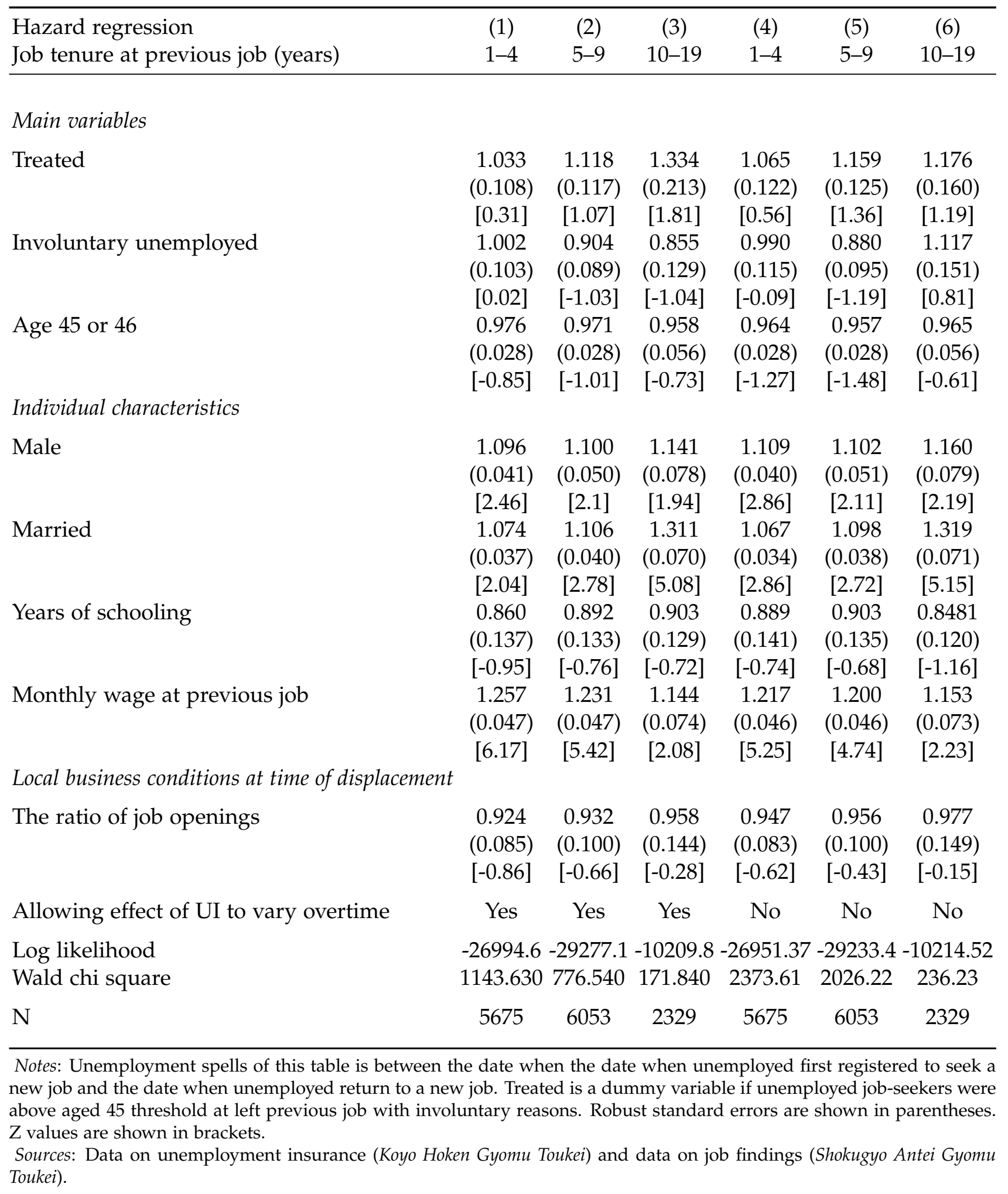


Table 5: Robustness Checks: The Results for Alternative Duration

\begin{tabular}{|c|c|c|c|c|c|c|}
\hline $\begin{array}{l}\text { Hazard regression } \\
\text { Job tenure at previous job (years) }\end{array}$ & $\begin{array}{l}(1) \\
1-4\end{array}$ & $\begin{array}{l}(2) \\
5-9\end{array}$ & $\begin{array}{c}(3) \\
10-19\end{array}$ & $\begin{array}{l}(4) \\
1-4\end{array}$ & $\begin{array}{l}(5) \\
5-9\end{array}$ & $\begin{array}{c}(6) \\
10-19\end{array}$ \\
\hline \multicolumn{7}{|l|}{ Main variables } \\
\hline Treated & $\begin{array}{c}1.116 \\
(0.135) \\
{[0.90]}\end{array}$ & $\begin{array}{c}1.172 \\
(0.125) \\
{[1.49]}\end{array}$ & $\begin{array}{c}1.369 \\
(0.219) \\
{[1.96]}\end{array}$ & $\begin{array}{c}1.084 \\
(0.126) \\
{[0.7]}\end{array}$ & $\begin{array}{c}1.169 \\
(0.131) \\
{[1.39]}\end{array}$ & $\begin{array}{c}1.204 \\
(0.161) \\
{[1.39]}\end{array}$ \\
\hline Involuntary unemployed & $\begin{array}{c}0.933 \\
(0.112) \\
{[-0.58]}\end{array}$ & $\begin{array}{c}0.913 \\
(0.095) \\
{[-0.87]}\end{array}$ & $\begin{array}{c}0.862 \\
(0.139) \\
{[-0.92]}\end{array}$ & $\begin{array}{c}1.005 \\
(0.116) \\
{[0.05]}\end{array}$ & $\begin{array}{c}0.902 \\
(0.098) \\
{[-0.095]}\end{array}$ & $\begin{array}{c}1.133 \\
(0.153) \\
{[0.093]}\end{array}$ \\
\hline Age 45 or 46 & $\begin{array}{c}0.967 \\
(0.028) \\
{[-1.18]}\end{array}$ & $\begin{array}{c}0.963 \\
(0.028) \\
{[-1.32]}\end{array}$ & $\begin{array}{c}0.951 \\
(0.053) \\
{[-0.91]}\end{array}$ & $\begin{array}{l}{[0.963]} \\
(0.027) \\
{[-1.34]}\end{array}$ & $\begin{array}{l}{[0.958]} \\
(0.027) \\
{[-1.51]}\end{array}$ & $\begin{array}{l}{[0.958]} \\
(0.053) \\
{[-0.78]}\end{array}$ \\
\hline \multicolumn{7}{|l|}{ Individual characteristics } \\
\hline Male & $\begin{array}{c}1.100 \\
(0.043) \\
{[2.41]}\end{array}$ & $\begin{array}{c}1.095 \\
(0.051) \\
{[1.95]}\end{array}$ & $\begin{array}{c}1.138 \\
(0.076) \\
{[1.93]}\end{array}$ & $\begin{array}{c}1.116 \\
(0.042) \\
{[2.92]}\end{array}$ & $\begin{array}{c}1.108 \\
(0.052) \\
{[2.19]}\end{array}$ & $\begin{array}{c}1.156 \\
(0.077) \\
{[2.19]}\end{array}$ \\
\hline Married & $\begin{array}{c}1.095 \\
(0.037) \\
{[2.67]}\end{array}$ & $\begin{array}{c}1.117 \\
(0.039) \\
{[3.18]}\end{array}$ & $\begin{array}{c}1.344 \\
(0.071) \\
{[5.56]}\end{array}$ & $\begin{array}{c}1.085 \\
(0.036) \\
{[2.51]}\end{array}$ & $\begin{array}{c}1.116 \\
(0.038) \\
{[3.18]}\end{array}$ & $\begin{array}{c}1.355 \\
(0.072) \\
{[5.65]}\end{array}$ \\
\hline Years of schooling & $\begin{array}{c}0.903 \\
(0.152) \\
{[-0.61]}\end{array}$ & $\begin{array}{c}0.908 \\
(0.141) \\
{[-0.63]}\end{array}$ & $\begin{array}{c}0.914 \\
(0.139) \\
{[-0.59]}\end{array}$ & $\begin{array}{c}0.916 \\
(0.150) \\
{[-0.53]}\end{array}$ & $\begin{array}{c}0.936 \\
(0.142) \\
{[-0.44]}\end{array}$ & $\begin{array}{c}0.865 \\
(0.131) \\
{[-0.96]}\end{array}$ \\
\hline Monthly wage at previous job & $\begin{array}{c}1.243 \\
(0.045) \\
{[6.03]}\end{array}$ & $\begin{array}{c}1.224 \\
(0.043) \\
{[5.73]}\end{array}$ & $\begin{array}{c}1.134 \\
(0.069) \\
{[2.05]}\end{array}$ & $\begin{array}{c}1.233 \\
(0.045) \\
{[5.75]}\end{array}$ & $\begin{array}{c}1.211 \\
(0.045) \\
{[5.19]}\end{array}$ & $\begin{array}{c}1.146 \\
(0.071) \\
{[2.21]}\end{array}$ \\
\hline \multicolumn{7}{|c|}{ Local business conditions at time of displacement } \\
\hline The ratio of job openings & $\begin{array}{c}0.911 \\
(0.087) \\
{[-0.98]}\end{array}$ & $\begin{array}{c}0.920 \\
(0.101) \\
{[-0.76]}\end{array}$ & $\begin{array}{c}0.951 \\
(0.148) \\
{[-0.33]}\end{array}$ & $\begin{array}{c}0.92 \\
(0.082) \\
{[-0.93]}\end{array}$ & $\begin{array}{c}0.927 \\
(0.099) \\
{[-0.7]}\end{array}$ & $\begin{array}{c}0.971 \\
(0.151) \\
{[-0.19]}\end{array}$ \\
\hline Allowing effect of UI to vary overtime & Yes & Yes & Yes & No & No & No \\
\hline $\begin{array}{l}\text { Log likelihood } \\
\text { Wald chi square }\end{array}$ & $\begin{array}{l}-26743.6 \\
2171.910\end{array}$ & $\begin{array}{l}-29088.1 \\
1564.150\end{array}$ & $\begin{array}{r}-10212.2 \\
353.930\end{array}$ & $\begin{array}{l}-27022.2 \\
2415.17\end{array}$ & $\begin{array}{l}-29320.8 \\
1654.02\end{array}$ & $\begin{array}{c}-10252.53 \\
262.92\end{array}$ \\
\hline $\mathrm{N}$ & 5675 & 6053 & 2329 & 5675 & 6053 & 2329 \\
\hline
\end{tabular}

Notes: Unemployment spells of this table is between the date when unemployed left a previous job and the date when unemployed return to a new job. Treated is a dummy variable if unemployed job-seekers were above aged 45 threshold at left previous job with involuntary reasons. Robust standard errors are shown in parentheses. $\mathrm{Z}$ values are shown in brackets.

Sources: Data on unemployment insurance (Koyo Hoken Gyomu Toukei) and data on job findings (Shokugyo Antei Gyomu Toukei). 